\title{
Proportional reasoning as a threshold to numeracy at university: A framework for analysis
}

\author{
Authors: \\ Pam Lloyd ${ }^{1}$ \\ Vera Frith \\ Affiliations: \\ ${ }^{1}$ Numeracy Centre, Academic \\ Development Programme, \\ University of Cape Town, \\ South Africa \\ Correspondence to: \\ Pam Lloyd \\ Email: \\ pamela.Iloyd@uct.ac.za \\ Postal address: \\ Private Bag X3, Rondebosch \\ 7701, South Africa \\ Dates: \\ Received: 14 June 2013 \\ Accepted: 02 Sept. 2013 \\ Published: 10 Oct. 2013 \\ How to cite this article: \\ Lloyd, P., \& Frith, V. (2013). \\ Proportional reasoning as \\ a threshold to numeracy \\ at university: A framework \\ for analysis. Pythagoras, \\ 34(2), Art. \#234, 9 pages. \\ http://dx.doi.org/10.4102/ \\ pythagoras.v34i2.234

\section{Copyright:} \\ (C) 2013. The Authors. \\ Licensee: AOSIS \\ OpenJournals. This work \\ is licensed under the \\ Creative Commons \\ Attribution License.
}

Read online:
There is a generally acknowledged need for students to be quantitatively literate in an increasingly quantitative world. This includes the ability to reason critically about data in context. We have noted that students experience difficulty with the application of certain mathematical and statistical concepts, which in turn impedes progress in the development of students' critical reasoning ability. One such concept, which has the characteristics of a threshold concept, is that of proportional reasoning. The main focus of this article is a description of the development of a framework using an adapted phenomenographic approach that can be used to describe students' experiences in the acquisition of the concept of comparing quantities in relative terms. The framework has also helped to make explicit the elements that constitute a full understanding of the requirements for the proportional comparison of quantities. Preliminary results from using the framework to analyse students' responses to assessment questions showed that many students were challenged by proportional reasoning. When considering the notion of the liminal space that is occupied en route to a full understanding of a threshold concept, about half of the students in the study were at the preliminal stage of understanding the concept and very few were at the threshold.

\section{Introduction}

It is commonly accepted that citizens need to be quantitatively literate (numerate) in order to participate effectively in an increasingly quantitative world (Department of Education, 2003; Gal, 2005; Jablonka, 2003; Steen, 2001). At our university we provide several first-year interventions intended to assist students to develop appropriate quantitative literacy for their disciplines (Frith, 2012). Amongst these is a context-based semester course that caters mainly for students studying law and humanities. The curriculum uses contexts that have a social justice focus in which students are exposed to some of the social issues that are important in a society in transition and that we judge to be relevant to both law and humanities students (Frith et al., 2010). An aim of the course is that students develop the ability to reason critically about quantitative data in such contexts. The focus of this article, which is part of a wider study, is on understanding how students experience the learning and application of a mathematical concept whose difficulty impedes progress in the development of this ability.

\section{The nature of quantitative literacy}

There are numerous definitions of quantitative literacy in the literature which emphasise various aspects of this complex concept. We adopt the following definition:

Quantitative literacy is the ability to manage situations or solve problems in practice, and involves responding to quantitative (mathematical and statistical) information that may be presented verbally, graphically, in tabular or symbolic form; it requires the activation of a range of enabling knowledge, behaviours and processes and it can be observed when it is expressed in the form of a communication, in written, oral or visual mode. (Frith \& Prince, 2006, p. 30)

The development of this definition was influenced by the definition of numerate behaviour underlying the assessment of numeracy in the Adult Literacy and Lifeskills Survey (Gal, Van Groenestijn, Manly, Schmitt \& Tout, 2005) and the view of literacy and numeracy as social practice (Prince \& Archer, 2008; Street, 2005; Street \& Baker, 2006).

The idea that quantitative literacy is mainly concerned with mathematics and statistics used in context is fundamental to all its definitions. In our definition the statement it requires the activation of a range of enabling knowledge, behaviours and processes' refers to the full range of competencies necessary for quantitative literacy practice, including mathematical abilities, logical thinking and thinking critically about data in context. Our definition also emphasises that responding appropriately to quantitative information in a text and communicating quantitative ideas are both essential components of numerate practice. 
Responding appropriately to quantitative information includes the ability to think critically about the meaning of such information. Most numeracy practitioners would agree that a disposition and ability to think critically about quantitative information is an essential aspect of numerate practice (Best, 2008; Jablonka, 2003; Johnston \& Yasukawa, 2001; Steen, 2001). For example, Johnston (2007) defines numeracy as 'a critical awareness that builds bridges between mathematics and the real world' (p. 54) and for Boersma and Willard (2008) the term quantitative literacy refers to 'the ability to reason critically with quantitative information' (p. 1). The literature on critical thinking (e.g. Facione, 2013) suggests that this critical awareness consists of mental abilities or cognitive skills, such as interpretation, analysis, inference, evaluation, explanation and self-regulation, and the disposition or habit of mind to use these mental abilities. According to Facione (2013, p. 10), '[t]he ideal critical thinker can be characterised not merely by her or his cognitive skills but also by how she or he approaches life and living in general.' Writers about numeracy have also stressed the importance of this critical habit of mind as a necessary attribute of a numerate individual (Dingman \& Madison, 2010; Steen, 2001).

The example presented in Figure 1 illustrates the interplay of the three facets of quantitatively literate behaviour outlined above, namely the application of mathematical concepts in context, critical reasoning and communication. When presented with data about the take-up rates of the Child Support Grant (CSG) in the various provinces of South Africa in 2005 and 2006, a spontaneous response by a quantitatively literate student could be the posing of the question: 'Which province was most successful in increasing the take-up rate of the CSG from 2005 to 2006?'

The process of answering this question involves reasoning about the size of the percentage change in each province by using information gained from the graphical representation and then communicating the result of this reasoning. The development of a framework to describe this ability in students is the focus of this article.

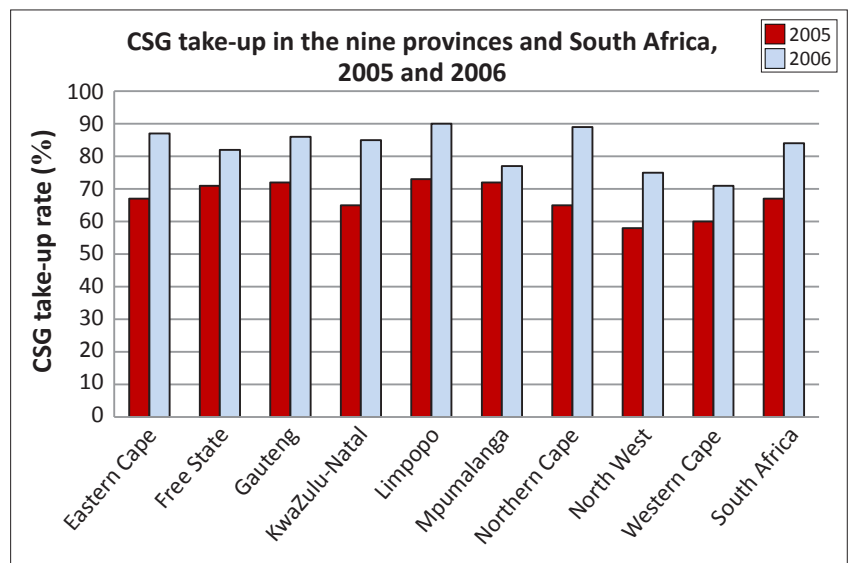

Source: Adapted from Leatt, A., Meintjes, H., \& Berry, L. (2006). Children's access to social assistance. In J. Monson, K. Hall, C. Smith, \& M. Shung-King (Eds.), South African child gauge 2006 (pp. 70-71). Cape Town: Children's Institute, University of Cape Town CSG, Child Support Grant.

FIGURE 1: Example of a data representation requiring critical interpretation.

\section{Background to current research question}

The initial aim of our research project was to determine to what extent we were effectively achieving the outcome that students are able to reason critically about data in context. However, once we began to consider our contextbased learning materials, our classroom interactions and the students' responses to assessment questions it became apparent that the students in these courses were hardly ever thinking critically in the way that we would like.

Reflection on why this was the case led to the realisation that too many of the students were still struggling at the level of understanding the mathematical concepts and techniques to allow for us to focus effectively on developing their critical awareness. Most of the classroom time was used for students to learn the basic mathematical and statistical concepts, leaving little time for drawing on these concepts in the process of thinking more critically about the contexts.

\section{Steen (2001) defines numeracy as}

[a]n aggregate of skills, knowledge, beliefs, dispositions, habits of mind, communication capabilities, and problem solving skills that people need in order to engage effectively in quantitative situations arising in life and work. (p. 7)

Drawing on this definition, we argue that our students in fact still need to acquire the skills and knowledge before we can effectively facilitate the development of appropriate habits of mind, communication capabilities and problem-solving skills. It is argued, for example by Bailin, Case, Coombs and Daniels (1999), that the extent to which one is able to think critically in a certain context, even if one possesses the cognitive skills and disposition to do so, will be determined by one's depth of knowledge and understanding of that context. In the case of quantitative literacy, this means that the critical awareness that is fundamental to numerate behaviour depends heavily on a sound knowledge and understanding of some basic mathematical and statistical concepts.

We thus decided that it would be more productive to first focus our attention on how students attempt to make sense of the mathematical concepts that they find to be difficult, with the ultimate aim of establishing more effective ways of teaching them.

\section{The problematic concept}

Through many years of teaching quantitative literacy courses we have repeatedly identified the concept of proportion and proportional reasoning as being problematic for first-year university students. Consequently, the curriculum of the course recognises that fractions, percentages and proportions are concepts that require revisiting - in various forms, at intervals, and in different contexts, with attention being paid to appropriate language use. Continual emphasis is placed on the use of the proportion concept in the comparison of quantities. Students are regularly exposed to situations where comparing quantities in absolute terms will give a very different impression from that gained by expressing 
each quantity as a fraction of some relevant base value before making the comparison. For example, one country may spend vastly more on health care than another with a similar population size, but as a proportion of its gross domestic product it could be spending far less. We believe that being able to move beyond thinking about quantities in absolute terms is crucial to the development of critical reasoning: the understanding of the concept of comparing quantities in relative terms and being able to identify situations where it may be relevant to do so is a very important tool for thinking critically about quantitative information. Ultimately we would like our students to spontaneously recognise when it would be appropriate to ask questions such as: Yes, this quantity is bigger than the other, but is it bigger in relative terms?

Despite the fact that almost all of our students have a school background that includes 12 years of Mathematics or nine years of Mathematics and three years of Mathematical Literacy, we have found that, for many of our students, even a basic understanding of the proportion concept and its use is lacking. Despite mediation during the course the problem is pervasive and persistent. In her work describing the challenges involved in understanding ratio by South African school learners, Long (2009, p. 34) notes that the development of proficiency in concepts such as fraction, ratio and rate is not confined to the early grades but continues through high school and beyond. Analysis of test items involving ratio, proportion and percentage revealed that, in general, Grade 8 learners in South African schools do not have an operational understanding of these concepts and are unable to solve problems in which these concepts are embedded (Long, 2009).

This problem is not confined to South Africa: research over a 30-year period by the Rational Number Project (n.d.) in the United States of America (USA) has resulted in over 90 publications focusing on the theory and practice of the teaching and learning of fractions in schools. It has been found that the representation of ratios and proportions as percentages presents particular difficulties. A review of research conducted in schools in the USA into the inadequate performance with percentages revealed that 'percent is a topic in which students have displayed inadequate performance, and in some cases utter confusion, for over 60 years' (Parker \& Leinhardt, 1995, p. 422). Investigating the difficulty in the learning of percentage, these authors drew attention to the mathematical complexity of the concept and the different ways in which it is used - to indicate a part-whole relationship; as a number, fraction or decimal; as an operator; and as a statistic or function. They also highlighted that the language of percentage uses concise and elegant linguistic forms requiring attention to unstated relationships and that this language is often in conflict with everyday language. In addition, they suggested that percentage is poorly taught and there is evidence that many teachers are also confused about the concept (Parker \& Leinhardt, 1995).
One of the strategies that many of our students appear to have adopted in order to cope with difficult mathematical concepts is to apply learned rules and procedures without much attempt at understanding. Parker and Leinhardt (1995) identify a problem in the teaching of percentage by means of fixed procedures that leads to students approaching problems by attempting to manipulate given numbers by rule, rather than by reason. We have observed that most of our students, when explicitly asked to do so, are able to calculate fractions such as percentage change by means of a formula when given the relevant quantities. That is, they are able to produce the 'ritual knowledge' described as the 'routine that we execute to get a particular result' (Perkins, 1999, cited in Meyer \& Land, 2006, p. 10).

However, the troublesome nature of proportion becomes apparent when students are asked to reason about change in a quantity as a percentage change, that is as a fraction, without doing calculations and then to describe in words, using appropriate language, their reasoning. Behr, Harel, Post and Lesh (1992) describe this kind of thinking as 'qualitative reasoning'.

We use the term 'proportional comparison' to describe the comparison of fractions that requires qualitative reasoning. Mastery of proportional comparison can be demonstrated when a student can compare change in two quantities in relative rather than absolute terms without making use of a formula or numerical values and can then use appropriate language to describe this reasoning. Typically, we have been interested in whether students are able to reason qualitatively about the effect that a change in the size of the numerator and/or denominator of a fraction has on the size of the fraction. An illustration of this is a question that we have asked students about the data for two of the provinces in the chart shown earlier in Figure 1. Since the data in the example is presented in graphical form it is possible, for example in the case of Limpopo and North West, to decide, without doing any calculations, which province experienced the greater percentage increase in CSG take-up rate. This is because both have experienced the same absolute change, but North West had a smaller take-up rate in 2005, resulting in a larger percentage increase for this province.

In order to ascertain the extent to which students have developed the ability to reason with proportions we examined students' answers to two assessment questions requiring the application of proportional comparison. In this article we focus on describing the development of the framework for elucidating the elements contributing to successful reasoning about proportional change. We then demonstrate the use of this framework to analyse student responses.

\section{Theoretical framework}

In developing our method of analysis we used the threshold concepts framework as described by Meyer and Land (2003) and a phenomenographic type of analysis (Marton \& Booth, 1997). 
We find that the threshold concepts approach provides a useful guide for thinking about how students understand concepts that are the foundations of numerate practice in higher education. According to Meyer and Land (2003),

[a] threshold concept can be considered as akin to a portal, opening up a new and previously inaccessible way of thinking about something. It represents a transformed way of understanding, or interpreting, or viewing something without which the learner cannot progress. As a consequence of comprehending a threshold concept there may thus be a transformed internal view of subject matter, subject landscape, or even world view. This transformation may be sudden or it may be protracted over a considerable period of time, with the transition to understanding proving troublesome. Such a transformed view or landscape may represent how people 'think' in a particular discipline, or how they perceive, apprehend, or experience particular phenomena within that discipline (or more generally). (p. 1)

These concepts are characterised as, amongst others, likely to be troublesome for the student; transformative, leading to a shift in perception and use of language; irreversible in that the change in perspective is unlikely to be forgotten; and integrative, in the way they link to other concepts in the discipline. So threshold concepts can be seen as gateways to thinking and practising and communicating authentically in a particular discourse.

The time taken for the process of internalising a threshold concept and thus effecting a transition from one way of thinking to another will vary depending on how troublesome the concept is for a student. During this time of transition a student may experience uncertainty and a sense of being stuck between a limited, superficial understanding of the concept and a full understanding; a student may well oscillate between stages of understanding. This conceptual space that is occupied by a learner is described by Meyer and Land as the 'liminal space':

Difficulty in understanding threshold concepts may leave the learner in a state of liminality (Latin limen - 'threshold') a suspended state in which understanding approximates to a kind of mimicry or lack of authenticity. (Meyer \& Land, 2003, p. 10)

Prior to the emergence of the threshold concepts theory, research in school mathematics education identified proportional reasoning as being both difficult for many students and as taking a long time to develop (Behr et al., 1992; Cramer \& Post, 1993; Karplus, Pulos \& Stage, 1983). More recently it has been recognised that fractions, ratios and proportions are amongst the most challenging mathematical concepts to learn and to teach (Lamon, 2007) and Long (2011, p. 211) asserts that there is 'agreement generally that proportional reasoning is a threshold concept'.

Given that many students entering higher education have not yet gained this threshold in school mathematics, we take the view that proportional reasoning is one of many mathematical and statistical concepts that often deny students access to numerate 'ways of thinking and practising' (Meyer \& Land, 2003, p. 12) in academic disciplines. This view is supported by the work of researchers in the sciences who have identified proportional reasoning as a threshold concept in their discipline. Ross et al. (2010) hypothesise that there is a 'web of threshold concepts' or 'epistemes', including proportional reasoning, that underlie difficult (in this case, biological) concepts.

\section{Method Data collection}

Data was obtained from the written assessments of students in the law course in the form of their responses to two assessment questions that required them to reason about percentage change. Permission for use of student work was obtained from students via a signed consent form in accordance with the requirements of the Research Ethics Committee of the Centre for Higher Education Development at our university. Students were informed that consent was voluntary and that anonymity would be respected. The work of students whose consent was not given was not used in this study.

The data was collected in two batches: we recorded each student's written response to a particular question in each of two assessments that were six weeks apart. Students regularly encounter contexts throughout the course where they are required to work with percentage change in various ways. Students continued to be exposed to contexts involving percentage change between the two assessments; however, we made no specific changes to the curriculum as a result of their performance in the first assessment. The intention of the questions was to assess students' ability to reason proportionally about data in previously unseen situations. The data in the assessment questions was presented graphically and students were instructed not to do any calculations but to explain their reasoning in a written response. In each case the reasoning required the comparison of the sizes of two fractions, the relative sizes of the fractions being apparent from the geometry of the graphical representation. Students had not previously discussed similar questions in which the data was presented graphically. See Appendix 1 for the actual questions.

Question 1 was set in the context of children's rights, specifically dealing with CSGs in South Africa and the takeup rates of CSGs in the different provinces. The chart used in this question is that shown in Figure 1. Although students had spent about five hours in class working with quantitative issues that arise in allocating resources for social services for children, including CSGs, the issue of take-up rate had not previously been encountered in classroom materials. However, in other contexts students had calculated percentage changes in quantities that were themselves percentages and been introduced to the difference between percentage change and change in percentage points. In Question 1, students were required to compare the percentage change in take-up rate for two specific provinces, North West and Limpopo. Careful observation of the graphs would show that the absolute change for both provinces was essentially the same, but for one province the percentage change was clearly calculated off a lower base. 
Question 2 was part of a later assessment at the end of the course. The context here was the real disposable income of South Africans and how this has changed over time. The data was again shown graphically, this time in the form of four time series, one for each of the different race groups ${ }^{1}$. The question itself required the consideration of the real disposable incomes of two of the groups, and how these had changed from 1960 to 2005. Students had been exposed to the concept of real income but had not previously compared relative changes in real income. As before, the absolute change for each group was approximately the same, but one clearly came off a lower base.

\section{Preliminary observations}

From a preliminary examination of student responses it was clear that most students had not reasoned about percentage change in the way we had expected. Many students compared the absolute changes instead of the relative changes and based their conclusion on the former comparison. Others based their argument on the comparison of only the absolute sizes of the quantities (without even considering the absolute change). In order to reason correctly about the relative changes, both of these elements must be taken into appropriate consideration. However, we observed that many of the students were focusing on only one or two elements of the necessary evidence and then jumping to a conclusion. They would also frequently not link the elements they identified in a logical way, and many did not use appropriate quantitative language to describe their observations.

We also realised that in both questions there was a large number of students who were distracted by the context in which similar questions had previously been experienced. For example, in Question 1 many students used arguments based on not knowing the population sizes of the different provinces. We suggest that the reason for this is that when they had previously been exposed to examples where they had to reason about proportions it was in situations where the quantities under consideration were percentages of a population. For example: in a tutorial, students studied a table in which the percentage of households with television was higher in Mpumalanga than in KwaZulu-Natal. They were then required to discuss the following question: 'Does this mean that Mpumalanga has more households with TV than does KwaZulu-Natal? Explain.' In the later question many students were distracted by the nature of the data representation. Much of their previous exposure to the interpretation of line charts involved making observations about trends and rates of change, and so it seems that many of them assumed that this kind of thinking was required in order to answer this question.

\section{Creating the framework}

We required a more precise description of students' understanding of proportional comparison. The framework

1.Race classification in South Africa is used as a social (rather than a biological) construct in the measurement of success (or otherwise) of transformation in society. for identifying and describing the elements that are required when reasoning about proportional comparison emerged from further examination of the data and applications of phenomenography suggested by the literature.

The phenomenographic method of analysis (Marton \& Booth, 1997) enables the description of the variety of ways in which people experience a phenomenon. This is usually achieved by means of open-ended interviews in which students reflect on their understanding of the phenomenon. The transcribed interviews are studied with the aim of categorising the descriptions of experiences in a way that will provide a limited, but complete, set of categories that covers all the variations. An iterative process is then embarked on where the interview data is re-examined using the categories and the categories are modified to ensure consistency with the data. The process continues until stability is achieved. The categories can often be arranged hierarchically, and a participant's experience may be described by one or more categories.

We adapted this approach by examining the written responses to assessment questions with the view to observing and categorising the ways in which students experienced proportional comparison. The variation in the ways of understanding the concept was described by an iterative process in which we read the students' responses and defined categories describing the different 'objects of focal awareness' (Marton \& Booth, 1997, p. 112) as experienced by students in their written responses, refined these categories and then coded students' responses according to these categories. This process is described below.

For the 36 responses to Question 1 and the 32 responses to Question 2, we independently identified preliminary descriptive categories and then coded student responses according to these categories. On comparing our categories we found that they were in effect the same and that our initial codings using our respective preliminary categories were very similar. At this stage it became apparent that the main categories were essentially descriptions of the elements required in the reasoning towards a correct answer: a consideration of the size of the absolute change, the size of the base from which the absolute change occurred, then a comparison of sizes of the resulting fractions.

These insights informed the development of new category descriptions that were general enough to be used to code the responses to both questions. This resulted in the framework outlined in Table 1. Using the framework and the coding key shown in the table we then independently re-coded the student answers. Agreement on a final coding was reached after further discussion. The stability of the framework was confirmed when, after a few months' break from the data and the framework, the coding exercise was repeated and only a few changes were made. 
TABLE 1: Coding key for Question 1 and Question 2

\begin{tabular}{|c|c|c|c|}
\hline Code & Description & Example of answers to Question 1 & Example of answers to Question 2 \\
\hline$A \dagger, \dagger$ & Compare the sizes of absolute changes & $\begin{array}{l}\text { Limpopo experienced the largest increase from } 2005 \text { to } 2006 \text {. In } \\
2005 \text {, the take up was } 74 \% \text { and it increased to } 90 \% \text { in } 2006 \text {. }\end{array}$ & $\begin{array}{l}\text { Indians; they had a greater increase between their } \\
1960 \text { values and } 2005 \text { values than the Whites. }\end{array}$ \\
\hline $\mathrm{B}+$, & $\begin{array}{l}\text { Recognise that absolute changes are } \\
\text { roughly equal }\end{array}$ & $\begin{array}{l}\text { Both provinces percentage point increase by } 20 \text {. Therefore } \\
\text { they experienced relatively the same increase in take-up from } \\
2005-2006 \text {. }\end{array}$ & No example in student answers \\
\hline$C \dagger, \$$ & Compare positions of initial values & $\begin{array}{l}\text { I would say that Limpopo experienced the greater increase } \\
\text { simply because the base year's value in Limpopo is higher than } \\
\text { that of the North west. }\end{array}$ & $\begin{array}{l}\text { The white Race Age Group because it had the highest } \\
\text { figures throughout. }\end{array}$ \\
\hline $\mathrm{D} \neq$ & $\begin{array}{l}\text { Recognise that percentage change is } \\
\text { relative and involves a fraction whose base } \\
\text { is important }\end{array}$ & $\begin{array}{l}\text { North West. Comes from a very small base compared to its } \\
\text { current end value in } 2006 .\end{array}$ & $\begin{array}{l}\text { Indians, as their income increased by roughly } 6 \text { times } \\
\text { during the period of } 1960-2005 \text {. }\end{array}$ \\
\hline $\mathrm{E}$ & $\begin{array}{l}\text { Misconception that larger denominator } \\
\text { means fraction is larger }\end{array}$ & $\begin{array}{l}\text { I would say Limpopo. Because Limp has a larger population and } \\
\text { the calculation would come off a larger base and would thus } \\
\text { yield a greater/larger percentage increase. }\end{array}$ & No example in student answers \\
\hline $\mathbf{F} \S$ & $\begin{array}{l}\text { Distracted by context in which this kind of } \\
\text { reasoning was previously experienced }\end{array}$ & $\begin{array}{l}\text { There is not enough information to say which increase was } \\
\text { larger. It depends on the size of the total population of eligible } \\
\text { children. }\end{array}$ & $\begin{array}{l}\text { Indians experienced the greatest percentage increase } \\
\text { because there is a more or less constant increasing } \\
\text { trend. This is opposed to the whites that experienced } \\
\text { a percentage decrease between } 1990 \text { and } 1995\end{array}$ \\
\hline Gף & $\begin{array}{l}\text { Correct conclusion correctly comparing } \\
\text { fractions, reasoning with components } A \text {, } \\
B, C \text { and } D\end{array}$ & $\begin{array}{l}\text { North west experienced the larger percentage increase from } \\
2005 \text { to } 2006 \text { than Limpopo. This is because we can see that } \\
\text { although the change in percentage points was similar, the } \\
\text { Northwest percentage point change is being divided by a } \\
\text { smaller base so its percentage change will be bigger than } \\
\text { Limpopo which is dividing over a bigger base. }\end{array}$ & No example in student answers \\
\hline $\mathrm{H}+\boldsymbol{T}$ & No appropriate explanation provided & $\begin{array}{l}\text { From looking at the two graphs it looks like North west province } \\
\text { had a bigger percentage change. }\end{array}$ & No example in student answers \\
\hline
\end{tabular}

$\dagger$, Answers that were coded A, B or C only are regarded as indicating the preliminal stage.

$\$$, Combinations of codes $A$ to $E$ (but excluding $\mathrm{G}$ ) are regarded as indicating the liminal stage.

$\S, \mathrm{F}$ can be present in preliminal or liminal stages.

I, At the threshold.

$\dagger$, Not classifiable.

\section{Using the framework for analysis}

Codes A, B, C and D are elements of a correct answer. Responses whose reasoning exhibited all four elements as well as the correct conclusion that the fraction with the smaller base will yield the larger percentage were coded only as G. Responses that showed incomplete reasoning were given one or more codes identifying the particular elements. In addition, responses of students who were distracted by the context in which they had previously been asked similar questions were coded as $\mathrm{F}$ and those whose reasoning was based on an incorrect understanding of fractions were coded as E. Those responses that we found incomprehensible or unable to classify were coded only as $\mathrm{H}$.

We then further classified students' responses in relation to the liminal space. Land, Meyer and Baillie (2010) describe the variation in the understanding of threshold concepts in terms of a journey through the preliminal, liminal and postliminal stages of conceptual development. According to our categories, codes A, B and C refer to answers in which students did not recognise that proportions were involved and referred only to absolute quantities or absolute changes. When viewed using the threshold concepts framework, these responses indicate that students do not appear to have engaged at all with the concept of proportional comparison and their understanding of the concept can be regarded as being at the preliminal stage. Codes D, E and F for Question 1 (and D and E for Question 2), sometimes in combination with codes A, B and C, represent understandings that are at various stages within the liminal space and $G$ represents an answer indicating that, at least in terms of the specific context of the question, the student has demonstrated mastery of the concept and its associated language. In this case their understanding can be considered to be at the threshold or, possibly, postliminal.

\section{Results and discussion}

In this section we present the results of an analysis, largely in order to illustrate the usefulness of the framework. For this reason we do not discuss the implications of the results in great depth. A summary of the coding of the responses to the questions is shown in Table 2. The total of the percentages is not $100 \%$, as many responses had multiple codes.

In Question 1, only 11\% of students, and in Question 2 only $3 \%$, correctly reasoned that it is the data category with the lowest initial value that has the greatest percentage change, given that in both cases the absolute changes were roughly equal. These responses indicate students being 'at the threshold'.

Table 3 shows a summary of the classification of responses as preliminal, liminal and 'at the threshold'.

More than one third of the students (42\% for Question 1 and $34 \%$ for Question 2) considered only the size of the absolute changes or did not consider change at all (and compared the size of the absolute quantities) and so did not recognise the need to compare fractions. We suggest that this demonstrates an understanding that is in the preliminal stage: the concept of proportional comparison did not 'come into view' (Meyer \& Land, 2005, p. 384). In particular, in Question 1, one quarter of the students argued that neither province had the greater change as the absolute change was the same for the two provinces (see Table 2). On the other hand, in Question 2, none of the students recognised that the absolute changes were essentially the same. Also, for this question we included in the preliminal classification those answers coded F, responses that indicated a focus on irrelevant trends shown by the graphs. 
TABLE 2: Results of coding of responses to Question $1(N=36)$ and Question 2 $(N=32)$

\begin{tabular}{|c|c|c|c|}
\hline \multirow[t]{2}{*}{ Code } & \multirow[t]{2}{*}{ Description } & \multicolumn{2}{|c|}{$\%$ of responses } \\
\hline & & Question 1 & Question 2 \\
\hline A & Compare the sizes of absolute changes & $19 \%$ & $22 \%$ \\
\hline B & $\begin{array}{l}\text { Recognise that absolute changes are } \\
\text { roughly equal }\end{array}$ & $25 \%$ & $0 \%$ \\
\hline C & Compare positions of initial values & $17 \%$ & $38 \%$ \\
\hline D & $\begin{array}{l}\text { Recognise that percentage change is } \\
\text { relative and involves a fraction whose } \\
\text { base is important }\end{array}$ & $31 \%$ & $19 \%$ \\
\hline E & $\begin{array}{l}\text { Misconception that larger denominator } \\
\text { means fraction is larger }\end{array}$ & $6 \%$ & $0 \%$ \\
\hline $\mathbf{F}$ & $\begin{array}{l}\text { Distracted by context in which this } \\
\text { kind of reasoning was previously } \\
\text { experienced }\end{array}$ & $25 \%$ & $50 \%$ \\
\hline G & $\begin{array}{l}\text { Correct conclusion correctly comparing } \\
\text { fractions, reasoning with components } \\
A, B, C \text { and D }\end{array}$ & $11 \%$ & $3 \%$ \\
\hline H & Incomprehensible & $11 \%$ & $6 \%$ \\
\hline
\end{tabular}

TABLE 3: Classification of responses to Question $1(N=36)$ and Question 2 $(N=32)$.

\begin{tabular}{lcc}
\hline Classification & \multicolumn{2}{c}{$\%$ of students } \\
\cline { 2 - 3 } & Question 1 & Question 2 \\
\hline Preliminal (A or B or C only) & $42 \%$ & $34 \%$ \\
(or F only, in the case of Question 2) & $36 \%$ & $31 \%$ \\
Liminal (combinations of A, B, C, D and F) & $11 \%$ & $25 \%$ \\
At the threshold (G only) & $11 \%$ & $6 \%$ \\
Not classifiable (H only) & & \\
\hline
\end{tabular}

More than one third of the students' responses in Question 1, and only one quarter in Question 2, showed an understanding that fractions needed to be considered. Some of these responses also noted the size of the absolute change but did not follow through with the correct argument. These understandings were considered to be in the liminal stage.

In the case of Question 1, one quarter of the students were distracted by the context and, instead of arguing using the data presented in the graph, tried to argue that the population size of the province would influence the percentage increase in take-up rate. As previously noted, the context of Question 2 appears to have been even more distracting, with half of the students including in their arguments irrelevant observations about the trends shown in the chart.

In this more distracting question some students, who were initially considered to be at the threshold, appear to have returned to the liminal stage, illustrating the observation of Land et al. (2010, p. xi) that 'the acquisition of threshold concepts often involves a degree of recursiveness', that is, a student's journey through the liminal space is not necessarily direct. We observed that not all students for whom understanding in Question 1 seemed to be at the threshold were (irreversibly) over the threshold and could therefore not be regarded as being in the postliminal stage.

\section{Conclusion}

One of the attributes of a quantitatively literate person is the ability to think critically about data in context. The outcomes of a quantitative literacy intervention at tertiary level that seeks to promote access to ways of thinking and practising in academic disciplines would include this ability. However, this particular outcome is unattainable if students are unable first to cross certain conceptual thresholds, one of which is that of proportional reasoning.

The development and application of a framework for the detailed analysis of student understanding of proportional comparison has enabled a systematic description of the range of student experiences in the process of gaining a full understanding of the concept. The development of this framework has made explicit the elements required when reasoning about proportions. It has also enabled the classification of student responses in relation to the liminal space that is occupied en route to a full understanding of proportional comparison.

Our study has shown that, throughout the course, and despite repeated exposure to the concept, most of the students retained an incomplete understanding of proportional comparison and almost half of the students remained in the preliminal stage. The study confirms the tenaciously troublesome nature of the concept and has implications for our teaching practice and the curriculum. These issues are to be the focus of future research.

\section{Acknowledgements}

We wish to thank Kate le Roux and Viki Janse van Rensburg for reading drafts of this manuscript and suggesting useful improvements.

\section{Competing interest}

We declare that we have no financial or personal relationships that may have inappropriately influenced us in writing this article.

\section{Authors' contributions}

P.L. and V.F. (both of University of Cape Town) contributed equally to the design of the assessment questions, analysis of student work, development of the framework, writing of the article and preparation of the manuscript for publication.

\section{References}

Bailin, S., Case, R., Coombs, J.R., \& Daniels, L.B. (1999). Conceptualising critical thinking. Journal of Curriculum Studies, 31(3), 285-302. http://dx.doi. org/10.1080/002202799183133

Behr, M.J., Harel, G., Post, T., \& Lesh, R. (1992). Rational number, ratio and proportion. In D. Grouws (Ed.), Handbook of research on mathematics teaching and learning (pp. 296-333). New York, NY: Macmillan Publishing.

Best, J. (2008). Beyond calculation: quantitative literacy and critical thinking about public issues. In B.L. Madison, \& L.A. Steen (Eds.), Calculation vs. context: Quantitative literacy and its implications for teacher education (pp. 125-135). Washington, DC: Mathematical Association of America. Available from http:// www.maa.org/sites/default/files/pdf/QL/cvc/CalcVsContext.pdf

Boersma, S., \& Willard, T. (2008). False positives and referral bias: Content for a quantitative literacy course. Numeracy, 1(2), Art. \#5. http://dx.doi. org/10.5038/1936-4660.1.2.5

Cramer, K., \& Post, T. (1993). Connecting research to teaching proportional reasoning. Mathematics Teacher, 86(5), 404-407.

Department of Education. (2003). National curriculum statement. Grades 10-12 (General) Mathematical Literacy. Pretoria: DOE.

Dingman, S.W., \& Madison, B.L. (2010). Quantitative reasoning in the contemporary world, 1: The course and its challenges. Numeracy, 3(2), Art. \#4. http://dx.doi. org/10.5038/1936-4660.3.2.4 
Facione, P.A. (2013). Critical thinking: What it is and why it counts. Millbrae, CA Measured Reasons and The California Academic Press. Available from http://www.
insightassessment.com/content/download/1176/7580/file/what\%26why2010. pdf

Frith, V. (2012). Quantitative literacy interventions at University of Cape Town: Effects of separation from academic disciplines. Numeracy, 5(1), Art. \#3. http://dx.doi. org/10.5038/1936-4660.5.1.3

Frith, V., Le Roux, K., Lloyd, P., Jaftha, J., Mhakure, D., \& Rughubar-Reddy, S. (2010) Tensions between context and content in a quantitative literacy course at university. In U. Gellert, E. Jablonka, \& C. Morgan (Eds.), Proceedings of the Sixth Mathematics Education and Society Conference, Vol. 1 (pp. 230-240). Berlin: Freie Universität Berlin. Available from http://www.ewi-psy.fu-berlin.de/en/v/mes6/ documents/proceedings/Band_1_Finale.pdf

Frith, V., \& Prince, R. (2006). Test domains and constructs and Appendix 2: Elaboration on the elements of the definition of Quantitative Literacy. In H. Griesel (Ed.), Access and entry level benchmarks. The National Benchmark Tests Project (pp. 28-34, 47-54). Pretoria: Higher Education South Africa.

Gal, I. (2005). Statistical literacy: Meanings, components, responsibilities. In D. BenZvi, \& J. Garfield (Eds.), The challenge of developing statistical literacy, reasoning and thinking (pp. 47-48). New York, NY: Kluwer.

Gal, I., Van Groenestijn, M., Manly, M., Schmitt, M.J., \& Tout, D. (2005). Adult numeracy and its assessment in the ALL survey: A conceptual framework and pilo results. In T. Scott, \& Y. Murray (Eds.), Measuring adult literacy and life skills: New framework for assessment (pp. 137-191). Ottawa: Statistics Canada.

Jablonka, E. (2003). Mathematical Literacy. In A.J. Bishop, M.A. Clements, C. Keitel, J. Kilpatrick, \& F.K.S. Leung (Eds.), Second international handbook of mathematics education (pp. 75-102). Dordrecht: Kluwer Academic Publishers. http://dx.doi org/10.1007/978-94-010-0273-8_4

Johnston, B. (2007). Critical numeracy? In S. Kelly, B. Johnston, \& K. Yasukawa (Eds.), The adult numeracy handbook: Reframing adult numeracy in Australia (pp. 5056). Sydney: NSW Adult Literacy and Numeracy Australian Research Consortium.

Johnston, B., \& Yasukawa, K. (2001). Numeracy: Negotiating the world through mathematics. In B. Atweh, H. Forgasz, \& B. Nebres (Eds.), Sociocultural research on mathematics education: An international perspective (pp. 279-294). Mahwah, $\mathrm{NJ}$ : Lawrence Erlbaum Associates.

Karplus, R., Pulos, S., \& Stage, E.K. (1983). Proportional reasoning of early adolescents. In R. Lesh, \& M. Landau (Eds.), Acquisition of mathematics concepts and processes (pp. 475-86). New York, NY: Academic Press.

Lamon, S.J. (2007). Rational numbers and proportional reasoning. Toward a theoretical framework for research. In F.K. Lester (Ed.), Second handbook of research on mathematics teaching and learning (pp. 629-666). Charlotte, NC: Information Age Publishing.

Land, R., Meyer, J.H.F., \& Baillie, C. (2010). Editors' preface. In J.H.F. Meyer, R. Land, $\&$ C. Baillie (Eds.), Threshold concepts and transformational learning (pp. ix-xlii). Rotterdam: Sense Publishers. Available from https://www.sensepublishers.com/ media/1177-threshold-concepts-and-transformational-learning.pdf

Leatt, A., Meintjes, H., \& Berry, L. (2006). Children's access to social assistance. In J. Monson, K. Hall, C. Smith, \& M. Shung-King (Eds.), South African child gauge 2006 (pp. 70-71). Cape Town: Children's Institute, University of Cape Town. Available from http://www.ci.org.za/depts/ci/pubs/pdf/general/gauge2006/gauge2006_ social.pdf
Long, C. (2009). From whole number to real number: Applying Rasch measurement to investigate threshold concepts. Pythagoras, 70, 32-42. http://dx.doi. org/10.4102/pythagoras.v0i70.37

Long, M.C. (2011). Mathematical, cognitive and didactic elements of the multiplicative conceptual field investigated within a Rasch assessment and measurement framework. Unpublished doctoral dissertation. University of Cape Town, Cape Town, South Africa. Available from http://hdl.handle.net/11180/1521

Marton, F., \& Booth, S. (1997). Learning and awareness. Mahwah, NJ: Lawrence Erlbaum.

Meyer, J.H.F., \& Land, R. (2003) Threshold concepts and troublesome knowledge: Linkages to ways of thinking and practising within the disciplines. Enhancin Teaching-Learning Environments in Undergraduate Courses Project, Occasional Report 4. Edinburgh: University of Edinburgh. Available from http://www.etl.tla. ed.ac.uk/docs/ETLreport4.pdf

Meyer, J.H.F., \& Land, R. (2005). Threshold concepts and troublesome knowledge (2) Epistemological considerations and a conceptual framework for teaching and learning. Higher Education, 49, 373-388. http://dx.doi.org/10.1007/s10734-0046779-5

Meyer, J.H.F,. \& Land, R. (2006). Threshold concepts and troublesome knowledge: An Introduction. In J. Meyer, \& R. Land (Eds.), Overcoming barriers to student understanding. Threshold concepts and troublesome knowledge (pp. 3-18). London: Routledge.

Parker, M., \&Leinhardt, G.(1995). Percent:A privileged proportion. Review ofEducationa Research, 65(4), 421-481. http://dx.doi.org/10.3102/00346543065004421

Prince, R., \& Archer, A. (2008). A New Literacies approach to academic numeracy practices in higher education in South Africa. Literacy and Numeracy Studies, 16(1), 63-75. Available from http://epress.lib.uts.edu.au/journals/index.php/Inj/ article/view/1948

Rational Number Project. (n.d.). The Rational Number Project. University of Minnesota. Available from http://www.cehd.umn.edu/ci/rationalnumberproject/

Ross, P.M., Taylor, C.E., Hughes, C., Kofod, M., Whitaker, N., Lutze-Mann, L., et al. (2010). Threshold concepts: Challenging the way we think, teach and learn in Biology. In J.H.F Meyer, R. Land, \& C. Baillie (Eds.), Threshold concepts and transformational learning (pp. 165-177). Rotterdam: Sense Publishers. PMCid:PMC3198851

South African Institute of Race Relations. (2009). South Africa survey online 2009/2010: Employment and incomes. Johannesburg: South African Institute of Race Relations. Available from http://www.sairr.org.za/services/publications/ south-africa-survey/south-africa-survey-online-2009-2010/downloads/ Employment.pdf/

Steen, L.A. (2001). The case for quantitative literacy. In L.A. Steen (Ed.), Mathematics and democracy: The case for quantitative literacy (pp. 1-22). Princeton, NJ: National Council on Education and the Disciplines and Woodrow Wilson Foundation. Available from http://www.maa.org/sites/default/files/pdf/QL/ MathAndDemocracy.pdf

Street, B. (2005). Applying new literacy studies to numeracy as social practice. In A Rogers (Ed.), Urban literacy. Communication, identity and learning in development contexts (pp. 87-96). Hamburg: UNESCO Institute for Education.

Street, B., \& Baker, D. (2006). So, what about multimodal numeracies? In K. Pahl, \& J. Rowsell (Eds.), Travel notes from the New Literacy Studies (pp. 219-233). Clevedon: Multilingual Matters. 


\section{Appendix 1}

\section{Question 1}

The Child Support Grant (CSG) is a cash grant to the value of R190 per month per child as of April 2006. Children are eligible for this grant if their primary caregiver and his or her spouse jointly have R800 per month or less in income and live in an urban area and formal house. Those who live in rural areas or informal housing in urban areas must earn R1100 per month or less to qualify for this grant. In July 2006, the CSG went to over 7.4 million eligible children aged 0-13 years. Using the General Household Survey 2004, Budlender calculated that some 8.8 million children are eligible for the CSG. This is $65 \%$ of all children under the age of 14 years. Using this eligibility rate, it is estimated that $84 \%$ of all eligible children access (or take up) CSGs across the country in 2006. There is substantial evidence that grants, including the CSG, are being spent on food, education and basic goods and services.

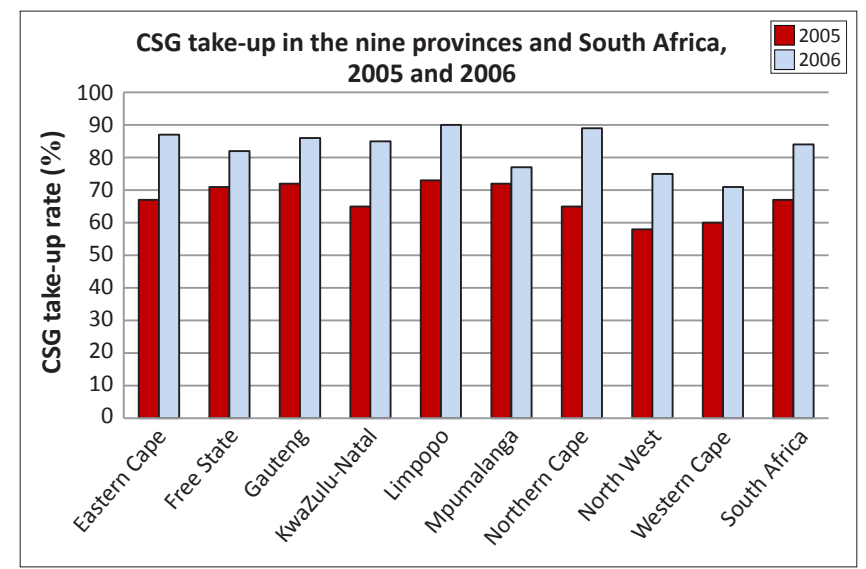

Source: Adapted from Leatt, A., Meintjes, H., \& Berry, L. (2006). Children's access to social assistance. In J. Monson, K. Hall, C. Smith, \& M. Shung-King (Eds.), South African child gauge 2006 (pp. 70-71). Cape Town: Children's Institute, University of Cape Town

Consider the take-up rates for Limpopo and North West provinces, as shown in the graph. Without doing any calculations, say which province experienced the larger percentage increase from 2005 to 2006 in CSG take-up rate. Explain your reasoning.

\section{Question 2}

The data in the chart below is taken from the South Africa Survey, 2009/2010 (South African Institute of Race Relations, 2009). Answer the questions about this chart below.

(Disposable income refers to earnings after taxes have been paid.)

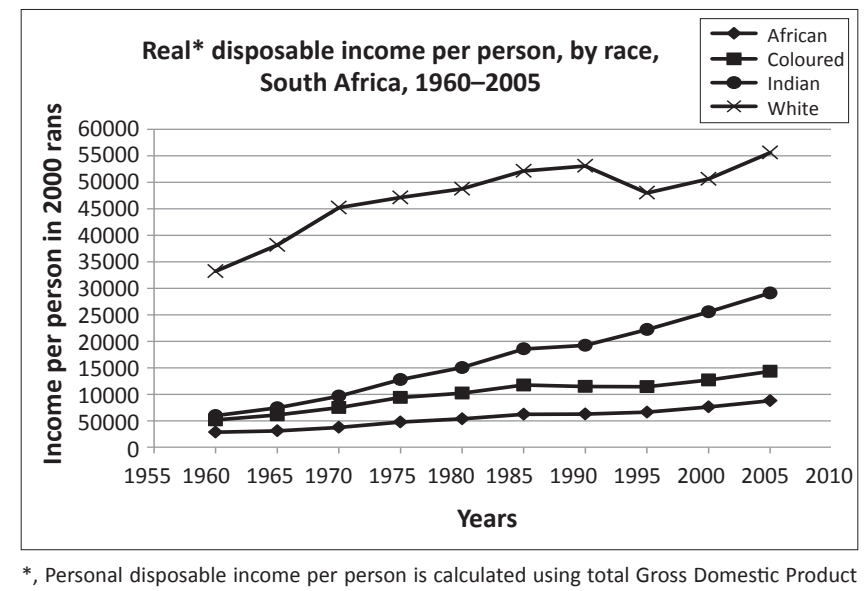

(GDP) divided by the total population. All incomes expressed using 2000 as the base year.

Consider the real disposable income per person for Indians and Whites. Without doing any calculations, say which race group experienced the greater percentage increase in real income per person from 1960 to 2005. Explain your answer. 